\title{
Evolution Is not enough: Revolutionizing Current Learning Environments to Smart Learning Environments
}

\author{
Kinshuk $^{1}$ • Nian-Shing Chen ${ }^{2}$ - I-Ling Cheng ${ }^{2}$. \\ Sie Wai Chew ${ }^{1,2}$
}

\begin{abstract}
Advances in technology in recent years have changed the learning behaviors of learners and reshaped teaching methods. This had resulted in several challenges faced by current educational systems, such as an increased focus on informal learning, a growing gap of prior knowledge among students in classrooms and a mismatch between individual career choices and the development of the work force. This paper looks at these challenges with a view towards revolutionizing current learning environments to smart learning environments and provides new suggestions for technological solutions. Furthermore, this paper argues for a transformation from the current learning environments to smart learning environments. This is to be achieved by reengineering the fundamental structure and operations of current educational systems to better integrate these new technologies with the required pedagogical shift. The future perspectives of smart learning environments are reviewed and shared, through examples of emerging innovations such as the flipped classroom, game based learning, gesture based learning, along with pedagogical shifts, such as life-long learning portfolio maintenance, team teaching, and separation of learning and competency assessment.
\end{abstract}

Keywords Smart learning environment $\cdot$ Reengineering education $\cdot$ Reorganizing schooling $\cdot$ Pedagogical innovations $\cdot$ Full context awareness $\cdot$ Learning analytics · Autonomous decision making

Kinshuk

kinshuk@ieee.org

1 Athabasca University, Athabasca, AB, Canada

2 National Sun Yat-sen University, Kaohsiung, Taiwan 


\section{Introduction}

With recent advancements in learning technologies, along with the ways information and communication technology (ICT) are implemented, many exciting possibilities have emerged to reshape students' learning behaviors and teachers' teaching methods. Regardless of how beneficial they may be, the education sector is known for being extremely slow in embracing change and in adopting technological advancements. The required pedagogical changes to make actual effective use of these technological advancements are even slower. Likewise, Price (2015) indicates that "while technology has changed what is possible to learn and how students can be supported in their learning, the principles of effective instruction have not changed"(p1). While early adopters' successful stories are not uncommon, current efforts for transforming existing schools to evolve and gradually adopt to these learning technologies are simply not enough. Though some initial efforts have already been made to reform the current learning environments, a revolution is needed to fundamentally transform the current learning environments towards smart learning environments. Smart learning environments go beyond simple application of technology. They enable the fusion of technology and pedagogy to create an ecosystem that involves active participation of teachers, parents and others in the learners' learning process. They also provide real-time and ongoing evidence of changes in knowledge, instilling skills which are seamlessly transferred to learners as they move from one learning context to another (Kinshuk 2016).

This paper begins with analyzing the problems of existing learning environments, along with the need for reform and innovations. It is followed by a discussion on the need for the emergence of smart learning environments. The paper also looks at the interplay of pedagogy, technology and their fusion towards the advancement of smart learning environments. From the pedagogical perspective, issues like learning paradigms, assessment paradigms and social factors are discussed. From the technological perspective, emerging technologies, innovative uses of mature technologies, and emerging/new technological paradigms are elaborated. Finally, from the perspective of pedagogy and technology integration, new curriculum, changes in teaching behavior, reengineering education, and reorganization of the existing school structure and operations are explored.

\section{The Problems of Current Educational Systems}

Over the past decade, it has been argued that technology-enhanced learning (TEL) could respond to the needs of the new knowledge society and transform learning (Chan et al. 2006) TEL can be perceived as a smart learning system (Hwang 2014). While there are indeed isolated achievements, TEL becomes a key consideration in the current revolutionizing of education and learning processes (Hwang 2014; Price 2015). This implies that a fundamental change of traditional schooling is needed: as said by Wirth and Perkins (2008), there is a "need for new kinds of learning" (p2). This section identifies three major challenges of current educational systems that require innovative uses of learning technologies to tear down the barriers and tackle the challenges. 


\section{Time Allocation Shift from Formal Learning to Informal Learning}

In the past, the primary channel for learners to gain knowledge was through formal learning in schools and universities. They spent something like $90 \%$ of their daily learning time in formal learning and very little in informal learning. However, learners' learning patterns and habits have been evolving along with the continuous growth of technology and the Internet. Nowadays, learners are no longer solely dependent on schools or universities to gain knowledge on a certain topic (Cross 2011; Bell et al. 2009). As ASTD (2008) indicates "Informal learning is used to supplement or reinforce learning from formal programs" (p15). Informal learning methods are easily accessible and available to learners via the Internet, resulting in a shift in the time allocation of formal learning to perhaps only $50 \%$ of the learners' daily learning time. The other $50 \%$ (or even more) of the learners' daily learning time is devoted to informal learning, such as online learning, virtual classrooms, or other online materials. This trend is moving faster than anyone could anticipate because there is an increasing number of better quality learning contents/courses available on the Internet (ASTD 2008; Bell et al. 2009; Conner 2008). With students spending less time in formal learning, it will only be a matter of time before informal learning replaces formal learning if formal educational systems do not change (ASTD 2008; du Bois-Reymond 2003). Traditional formal educational systems desperately need to make fundamental change to strive for a better survival of formal education.

\section{The Growing Gap of Prior Knowledge among Students}

With the rapid growth of the Internet today, information is retrievable anywhere and anytime. With a tap on the smartphone or a click on the laptop, learners are able to search for relevant facts on any topic or subject matter (ASTD 2008). As a result, educators are increasingly faced with the problems of preparing and structuring formal courses to accommodate learners with different knowledge levels on a subject matter. Learners with prior knowledge on the subject may otherwise find the course dull. As McNeely (2005) indicates, “... the Net Generation... all use computers in their class work and in their hobbies. They have a wide range of interests, outside their chosen area of study... They learn by doing, not by reading the instruction manual or listening to lectures" ( $p$ 4.3).

Yet, there are others, who may not have been exposed to a subject and they require appropriate content delivery from the educator. As mentioned by Clayton-Pedersen and O’Neill (2005), “education must enable individuals to discover what they need to know rather than just having static knowledge". Hence, the increasingly large gaps in prior knowledge about the subject matter among learners make it difficult for educators to maintain learners' engagement in the class.

\section{Mismatch in Individual Career Path with the Development of the Work Force}

Development and expansion of technologies are fueling a dynamic change in our society, including industries and corporate organizations. New forms of industries 
and new types of jobs are emerging, requiring future personnel to be well equipped to meet the need of the expansion requirements of these industries and keep up with their development needs. Learners and students, being the future drivers of these industries, are the main human resource to fulfill the vacancies of these work forces. However, with the current formal learning provided in schools and universities, learners are not well equipped nor prepared for the new kinds of jobs, making it difficult for them to fulfill the work-force demands of the future. Therefore, constant improvements in and reevaluation of the curriculum taught to the learners has to be done regularly to keep the learners up-to-date in fulfilling the requirements of these industries and corporations.

With the work demands changing at a rapid pace, corporations are instilling the education element into their working environment by transforming their working environment into a learning environment for their employees. For example, Google and IKEA provide extensive learning opportunities for their employees while they are on the job. This not only provides employees with an innovative environment to learn and grow, but also gives them the positive urge to venture into new products and come out with creative ideas benefiting the organizations. Universities could benefit from these "thinking out of the box" practices by equipping students with work force experience that involves more hands on task with corporations and companies. Many universities have started to adopt co-op and internship programs to facilitate these experiences, particularly in engineering and computer science programs. For example, University of Waterloo offers co-op that provide students to "alternate 4-month school terms with 4-month paid work terms in jobs relating to your program" (https:// uwaterloo.ca/find-out-more/co-op). Universities would then be setting courses which are more relevant to the actual field work by putting themselves in the field itself, equipping students with all the skills and knowledge required in the work field.

\section{Emergence of Smart Learning Environments}

Due to rapid advances of information and communication technology (ICT) in recent years, learning technologies have already impacted and changed the educational landscape significantly. In order to provide learners with a learning environment that makes effective use of technological advances, teaching methodologies and learning strategies also require changes. For example, cyber synchronous learning, mobile learning, social learning, and ubiquitous learning did not exist in the past educational landscape. As mentioned by Hwang (2014), "new learning modes will raise new pedagogic issues" (p11). Thus, new teaching methodologies and learning strategies are desperately needed in the current education systems to support these newly emerging modes.

This section discusses the case of employing innovative learning technologies in ubiquitous settings, as an example of the emergence of smart learning environments. This is where learning benefits from authentic environments. The environment is not restricted only to formal educational activities, but also encompasses informal learning opportunities that result in improvement of the learners' overall knowledge and skill levels. In other words, smart learning environments engage and integrate formal and informal learning in order to create autonomous adaptive learning environments for supporting individual learners with real-time and seamless learning experiences in 
ubiquitous settings. As Hwang (2014) indicates, "A smart learning environment not only enables learners to access digital resources and interact with learning systems in any place and at any time, but also actively provides the necessary learning guidance, hints, supportive tools or learning suggestions ... in the right place, ...right time and ... right form" (p2).

These environments typically use big data and learning analytics techniques to synthesize the combination of real-time data and the historical datasets in order to identify contextually meaningful learning patterns. Smart learning environments facilitate just-in-time learning as they can provide various levels of adaptation and precision of diversified learning conditions (including curriculum, course content, strategy and support, etc.) for the learners. As mentioned by Boulanger et al. (2015), "a smart cloud computing framework...consists of four basic services:... "the pull service will extract the type of content to be delivered to the users. The prospect service is responsible for the preparation of the learning content to comply with user context. The content service generates the content and establishes the connection between the server and the target device....the push service performs the synchronized delivery of the generated content to the target device. (p290)".

Three major features of the development of smart learning environments are discussed that separates smart learning environments from other advances in learning technologies. The three features/directions are full context awareness, big data and learning analytics, and autonomous decision making.

\section{Full Context Awareness}

Abowd et al. (1999) indicated that “...context-awareness or context-aware computing is the use of context to provide task-relevant information and/or services to a user. Three important context-awareness behaviors are the presentation of information and services to a user, automatic execution of a service, and tagging of context to information for later retrieval" (p304-305). Traditional learning environments are not fully context-aware systems. For example, teachers and educators are not aware of every learner's learning behavior, learning process and learning outcomes in real time in a traditional learning environment.

Boulanger et al. (2015) indicated that smart learning environments involve contextawareness that can combine a physical classroom with many virtual learning environments. This could provide full context awareness by combining smart learning environments with holistic Internet of Things (IOT) and ubiquitous sensing devices, e.g., wearable technologies such as smart watches, brainwave detection, and emotion recognition ( $\mathrm{Li}$ et al. 2015; Hwang 2014). Full context awareness enables smart learning environments to provide learners with authentic learning contexts and seamless learning experiences to fuse a variety of features in the e-learning environments. The system includes learning management systems, mobile and ubiquitous learning systems, various artificial intelligence based adaptive and intelligent tutoring/learning systems. These systems would assist teachers and instructors in direct monitoring of the learning environment, understand learners' conditions and give learners real-time adaptive assistance, while at the same time facilitating independent learning for the learners (Chan et al. 2006; Hwang 2014; Schilit et al. 1994). 


\section{Big Data and Learning Analytics}

Smart learning environments are expected to facilitate smart learning support that is based on each individual learner's learning profile. Smart learning environments need to consider advanced data manipulation techniques such as employing big data and learning analytics to collect, combine and analyze individual learning profiles (from past to present) in order to scientifically generalize and infer each individual learning need in real time in ubiquitous settings that encompass both physical and online activities. Learning analytics by using big data can monitor individual learners' progress and behavior continuously in order to explore factors that may influence learning efficiency and effectiveness (Kumar et al. 2015a, b). However, providing each learner with just in time adaptive learning support through effective application of full context awareness is still a challenge for TEL. As Boulanger et al. (2015) pointed out, "the degree of customization, the scalability of ubiquity, and the integration of learningrelated data are still key challenges facing educational technologists" (p289). However, Price (2015) indicated that "to develop a smart learning environment, it is important to monitor, refine, and improve the components of the efforts continuously. The purpose of using advanced data techniques is to gain insights about an individual learner's learning experiences, to tailor instruction to individual learner's needs, and to equip the learning environment with relevant and/or optimal learning conditions (in terms of curriculum, course content, strategy and support, etc.) (Boulanger et al. 2015; Kumar et al. 2015a, b). Price (2015) further stated that "successful education reform should be based on future outlook, and should incorporate program data from the outset in regular evaluations and measurements ...for the successful education transformation... it must deliver sustained value and drive toward continuous improvement in student performance" (p12). Thus, through big data and learning analytics, smart learning environments could derive new and more effective learning models by analyzing the data collections of various learners and further extract valuable learning patterns, to provide suggestions and recommendations to the learners over long periods of time, possibly even during their future careers.

\section{Autonomous Decision Making and Dynamic Adaptive Learning}

Another important feature of smart learning environments, which is different from other learning environments, is their autonomous knowledge management capability that enables them to automatically collect individual learners' life learning profiles. As Kay (2008) mentioned, learners' life learning profiles can track their learning progress over long periods and across the range of sources of evidence about the learner's progress. Based on individual life learning profiles and the techniques of big data and learning analytics, smart learning environments can precisely and autonomously analyze learner's learning behaviors in order to decide in real time, for example, what interactions with the physical environment to recommend to the individual learners to undertake various learning activities, the best location for those activities, which problems the learners should solve at any given moment, which online and physical learning objects are the most appropriate, which tasks are the best aligned with the individual learner's cognitive and meta-cognitive abilities, and what group composition 
will be the most effective for each group member's learning process. Such autonomous decision making and dynamic adaptivity has the potential to generalize and infer learners' learning needs in order to provide them with suitable learning conditions.

It is a challenge for smart learning environments to collect these data about the learners and their environment from disparate sources in both physical and online components of the ubiquitous settings. For smart learning environments to possess autonomous decision making capability that could utilize learning analytics features to provide individual adaptive learning support is important. As Spector (2014) points out, it is necessary for a smart learning environment to autonomously provide "different learning situations and circumstances, as... a human teacher or tutor... to help learners become more organized and aware of their own learning goals, processes and outcomes" (p7).

\section{Pedagogical Innovations in Smart Learning Environments}

This section looks at the need for the shift in pedagogies to support new requirements of learning. Some examples of pedagogical innovations are discussed, and while the list is not exhaustive, it identifies critical differences that set smart learning environments apart from traditional approaches.

\section{Knowledge Generated from Micro-Social Interactions}

Knowledge in smart learning environments is not restricted to formal learning situations any more. There is an increasing realization that learning can and does happen in any environment, interaction and conversation that the learners engage in (Dabbagh and Kitsantas 2012). In particular, when the learners engage in social media, such as browsing Facebook posts, reading tweets on Twitter, looking at pictures on Flickr or Instagram, or simply having a conversation with someone on Skype or WhatsApp (Kinshuk 2014), the challenge for a smart learning environment is to identify the moments of "opportunistic learning" by analyzing those micro-social interactions for possible knowledge nuggets and integrating them with the learner's previously gained knowledge.

\section{Change in Assessment Practices to Include Knowledge Generated from Micro-Social Interactions}

For effective integration of knowledge generated during micro-social interactions with the previously gained knowledge, the assessment practices also need reconsideration. Formal assessment methods, such as two-hour final exams in an examination room using paper and pen, or quizzes on computer, do not provide adequate means to assess the knowledge nuggets the learners have acquired during their social interactions or the integration of those knowledge nuggets with previous knowledge to expand their understanding (Kinshuk 2015). New assessment methods are needed to analyze the knowledge gains due to social interactions as well as their impact on the overall competence level of individual learner. Learning analytics approaches enable such assessment by identifying patterns in the learner's behavior and use the gained knowledge at a fine grain to be able to detect the impact of micro level gains. 


\section{Assessment in Ubiquitous Learning Environments}

Recent advances in the mobile and sensor technologies have started to give rise to research and development that takes advantage of a learner's location, environment, proximity and situation to contextualize the learning process (Kinshuk 2014). Adaptivity and personalization in this kind of ubiquitous learning context have taken on a new meaning by bringing authenticity (Kinshuk 2014), through seamless integration of physical objects available in the learner's vicinity with virtual information in real-time. For example, environments not only break barriers to education by widening access to those who cannot attend a physical classroom, but also increase the richness of instruction by integrating multiple sources of instruction, contextualization and realtime location-aware learning. Hence, overcoming the limitations of classroom learning, assessment for ubiquitous learning also needs a shift from traditional assessment approaches. Some examples of the assessment needs in ubiquitous learning environments are as follows:

(a) What capabilities and competencies do learners possess with respect to ubiquitous learning opportunities, and what are their preferences with respect to the associated authentic learning environment and learning process?

(b) What are the ways in which meaningful movement and interaction patterns of individual learners can be detected and analyzed? How do those movements and interactions relate to the interactions and learning activities at a particular authentic learning location?

(c) What is the influence of the technologies that are accessible to the learners at a given point in time, on their learning experiences? What influence do the technologies surrounding the individual learners have on learners' learning experiences?

(d) How do various components of context relate to the current situation of individual learners, and how do those components affect each other?

\section{Real-Time Intervention in Learning}

Real-time interventions in learning require mining of relevant information about the learners from various sources and aggregating that information for "ubiquitous learning analytics" in order to provide real-time recommendations to improve the effectiveness of the learning process. These information nuggets need to be presented using advanced visualization techniques and smart technologies to enable natural interaction through rich interfaces, and help investigate and analyze learners' behavior, activities, and performance in ubiquitous (field) environments (Mottus et al. 2015). Advanced data mining techniques need to be designed to identify relevant patterns, such as where and when learners have difficulties and where their strengths lie (Kumar et al. 2014). Teachers in such environments are able to intervene in the learning process and provide learners with advice and support, such as explaining the topic/tasks, pointing to particular learning material, providing learners with the activities that could help them understand the particular topic/task, and creating teams with complementary strengths. In addition, teachers can receive personalized and intelligent support through analysis 
of their preferences and can adapt their teaching accordingly. Techniques also need to be designed using, say, machine learning approaches to infer how different teachers respond in certain situations, which kind(s) of support they provide to their learners, as well as how a particular teacher previously responded in certain situations. Based on this analysis, suggestions and guidelines can be offered as and when a teacher is found in a similar situation.

\section{Technological Innovations in Smart Learning Environments}

Smart learning technology can support learners in both real and virtual environments. The emerging technical innovations now enable us to effectively record and analyze learners' learning patterns and habits. Based on each learner's learning profile, they provide educators and learners with a customizable and personalized approach to learning. Using these technologies, teaching approaches can change to fit the needs of the learners, making it possible for the teachers to monitor an individual learner's learning process at a much finer granularity. Moreover, learners can be given the opportunity to choose and shape their own learning portfolios and fill such portfolios with actual evidence of learning.

In the near future, these technologies will progress into greater maturity in executing seamless monitoring and autonomous adapting to the learners' learning needs. These technologies would enable spontaneous information feeding to learners, providing learners with learning materials fitting their needs, interests and learning habits. Furthermore, instantaneous reflection and review of the learners' learning progress would be possible, along with instant feedback by the environment to assist learners with their enquiries. This would make it possible to provide "always-on" learning independent of location and device/platform.

There are thousands of technologies that have been implemented into TEL. This section takes a look at some examples of innovative technologies used in smart learning environments that enable learning opportunities and instructional interventions that have been very difficult, if not impossible, in traditional settings.

\section{Flipped Classroom}

The concept of a flipped classroom has emerged in recent years as one of the popular methods used for enhancing teaching quality and improving learners' outcomes. The idea is to flip the traditional in-class lecture so that the students take a vital role through collaborative activities (McLaughlin et al. 2014). This method has gained particular interest in K-12 education (Chen et al. 2014). The flipped classroom approach enables teachers to provide students with different learning opportunities in the course as they move through the curriculum (Fulton 2012). By integrating various learning technologies in the classroom, the flipped classroom approach has shifted the instruction from a teacher centered physical classroom, to a student centered blended learning environment (Chen and Chen 2014). Flipped classrooms allow teachers to deliver the course content in a more interactive manner, along with interactive learning activities both inside and outside of the physical classroom (Cheng et al. 2015). They include both formal and informal learning approaches, enriched with interesting and interactive 
learning activities to increase students' engagement in the course and enhance their learning process.

\section{Massive Open Online Course (MOOC)}

The concept of Massive Open Online Course (MOOC) has emerged as another popular method in recent years, enabling learners to attend online courses anytime and anywhere. MOOCs are designed to provide learners with free access to open education and these courses are capable of having intakes of vast number of participants through the Internet (Chew et al. 2015). They allow everyone across the globe to pursue more knowledge with no limitation on the number of student intake and enrollment period (Riddle 2012). Learners taking MOOCs have the flexibility to complete each course at their own pace, to suit with their own schedule. MOOCs enable self-directed learning where learners can achieve their own learning needs and goals by applying appropriate personal learning strategies (Paquette et al. 2015). MOOCs are typically equipped with interactive video lectures and learning activities to engage learners in the learning process. Both asynchronous learning and synchronous learning modes are possible with MOOCs, allowing and increasing the interaction among the learners and between the learners and the instructors (Chen et al. 2005; Hastie et al. 2010) to facilitate better learner experience.

\section{Game-Based Learning}

Game-based learning involves integrating learning and curriculum into computer games, providing learners with a virtual environment to enjoy the game and have fun while learning the curriculum. Compared to instructional or formal learning methods, learners typically spend more time engaged with computer games, which has resulted in educators and researchers examining the potential of game-based learning as a serious component of instruction. For example, Tobias et al. (2014) have argued that game-based learning can assist in enhancing learners' cognitive processes and cultivate multitasking skills in the learners. Furthermore, game-based learning has been found to enhance learners' self-efficacy and assist in increasing knowledge retention (Sitzmann 2011). It is worth noting that the work of engineering a game to meet a specific learning task or need becomes a challenge or barrier when trying to scale it towards many learning tasks.

\section{Augmented Reality and Virtual Reality}

Augmented reality (AR) is defined as "a live direct or indirect view of a physical, realworld environment whose elements are augmented (or supplemented) by computergenerated sensory input" (Wikipedia n.d.). Virtual reality (VR), on the other hand, is a simulated real-world environment that is created to enable users to believe that the environment is real. Both AR and VR can be used for education by simulating a real environment during the instruction process, providing learners with a better understanding and visualization of the subject matter (Kaufmann 2003). With the pervasive growth of the Internet of Things and wireless sensor networks, plus the wide accessibility of wearable technologies/devices, AR/VR technologies can be used to convert our physical contexts into 3D immersive learning environments that seamlessly 
integrate physical and digital worlds. A whole new learning experience with authentic, situated and timely response features is emerging. This obviously brings with it a great challenge of constructing a broad range of learning scenarios to be used in these virtual learning environments.

\section{Gesture-Based Learning}

Gesture-based learning incorporates gesture-based technologies in the learning process, allowing learners to engage in a virtual environment by interacting with computers primarily using their body motions and movements. Gesture-based technologies consist of various sensors, such as gravity sensor, infrared sensor and structured-light 3D sensor, enabling gesture recognition (body actions and movements), voice recognition, and positioning (action acceleration and direction changes) (Johnson et al. 2012; Hung et al. 2014). Through the theory of embodied cognition used as the main pedagogical approach, gesture-based learning provides opportunities for the learners to actively and physically engage in various hands-on learning activities (Chao et al. 2013). Gesture-based learning enhances learners' body-related experiences through the use of actions as part of the learning process, which intensify the learning and cognitive processing through motor-sensory experience (Chen and Fang 2014). The major challenge of designing gesture-based learning is the lack of design principles and guidelines for systematic development.

\section{Educational Robots}

Robots are mechanical artificial agents guided by computer programs. They are now widely used in various industries, such as manufacturing, production and medical sectors. With the ability to imitate lifelike automated movements, robots are capable of assisting in solving various problems. In terms of education, robots can provide a social and physical embodiment to the concept of teaching, assisting teachers in continuous and repetitive follow ups with the learners. For example, in language learning, robots have been successfully used to assist learners by repeating phrases over and over again without the problem of getting tired (Mubin et al. 2013). With educational robots, learners do not feel shy in asking questions and the robots can assist learners in solving their enquiries immediately anytime and anywhere. Besides, educational robots can enrich the subject curriculum and increase learners' attention and engagement in the learning process. Thus, the robots in education have potential to play the role of a personal tutor for learners, understanding the learning needs of each learner and customizing the learning contents according to individual learners' pace and requirement. The advancement in data mining, big data analysis and learning analytics have strong potential to become the backend engines for implementing more sophisticated intelligent educational robots.

\section{Future Perspectives of Smart Learning Environments}

The learning process is increasingly integrated into every aspect of life including conscious, unconscious, intentional and/or unintentional situations (Malcolm et al. 2003). It implies immersive, always-on learning that needs to happen naturally and in such small chunks that virtually no conscious effort is needed to be actively learning 
while engaged in everyday life (Mottus et al. 2015). Smart learning environments need to be so much in tune with their learners that they are aware of every interaction the individual has with the environment. In particular, because smart learning environments are personalized to cater for individual learner's needs in all types of situations, every bit of information that each learner comes into contact with needs to be taken into account. To meaningfully support a learner's learning process through smart learning environments, assessment of such learning also requires fundamental changes in current practices and in the mindsets of educators and other stakeholders in order to ensure effective learning in a wide variety of contexts and for individuals with a wide variety of prior experiences and backgrounds. This section will discuss these issues of smart learning environments by focusing on the integration of pedagogy and technology through a variety of perspectives.

\section{Life-Long Profiling}

Learning portfolios, that include not only the traditional learner models depicting the change in learners' knowledge and skills but also the evidence of learners' competency gains in the form of learners' artifacts, have long been implemented in the academic field for profiling past and ongoing learning progress, serving as meaningful tools to assess and demonstrate one's learning capabilities (Kay 2008). They provide learners with opportunities to reflect on their work, access to an organized record and systematically demonstrate the accomplishments. So far, learning portfolios have been used on a course-by-course basis. For example, the portfolio of a certain course is discontinued when the learner completes that course and a new portfolio is created for the next course the learner enrolls in. Moreover, learners' learning could be conscious, unconscious, intentional and/or unintentional (Malcolm et al. 2003). Thus, all the portfolios created by the learner during their entire program remain disconnected. We argue that the use of these portfolios should be extended to a life-long profiling, carried from one course to another, bridging the learning gap between courses, or even transcending from formal and informal education on to the continuous learning taking place later in life that connects to the learner's career development.

In order to achieve this, a life-long learning profile can be stored on the cloud, combined with social media at a macro level, which uses learning analytics/big data to automatically provide recommendations and/or record achievements within the lifelong portfolio. Such a portfolio will not only connect to a formal learning system to gather achievement data, but it will also identify skills and knowledge gained during any social media interactions, based on the access permissions set by the learner. Although life-long learning may require a lot of big data techniques or AI techniques, it will help in analyzing the learning process and product, providing both the bigger picture and also allowing drilling down to the associated evidence. This would enable learners to build their digital life online whereby they could consistently reflect on their learning and share accomplishments Kinshuk (2014)

\section{Team Teaching}

In traditional schools, course teachers are solely responsible for preparing the lecture notes, assigning homework, creating final exam questions, and so on. As is true for the 
learners, the teachers also have different individual strengths, such as specific expertise in particular knowledge content, the ability to give lectures to large classes versus providing explanations in small groups, the creation of open ended questions for group based assignments versus meaningful multiple choice questions to assess individual competence, etc. Going forward, smart learning technologies can enable teachers to consider forming alliances with other teachers, locally as well as remotely to conduct team teaching in order to make plans, organize teaching materials, and categorize various teaching activities based on individual teacher's strengths and expertise to enhance teaching quality as well as quality of course content. Team teaching can cater to various teaching contexts, ranging from large group activities to serving the unique learning demands of differentiated learners since different teachers may look at a topic from a different angle (Leavitt 2006). Although team teaching may cause some problems, for example, when teachers debate an issue or propose different solutions to a particular question, this can potentially result in enriching course teaching techniques as well as reduction in the ever increasing teaching loads of individual teachers (McDaniel and Colarulli 1997). Learners, moreover, could receive the best learning experience in every learning activity, as each activity will be supported by the teacher who is the best suited to teach that activity. In other words, team teaching allows a learner to understand a concept/topic from multiple perspectives through different scholars with different teaching skill sets (Leavitt 2006).

Additionally, team teaching would also solve the resource constraints traditional schools typically experience due to restrictions imposed by the local conditions such as classroom size. For example, a teacher may teach a maximum of 35 to 40 students in a class due to space constraints and other similar restricting factors. Thus, it is common for the learners to not be able to enroll in a course that they are very much interested in, if the demand for that course is high. Team teaching, supported by the advances in technology eliminates those restrictions, enabling thousands of learners around the world to enroll in courses of their choice and interest. Therefore, team teaching is a way for schools to not only provide the best education by harnessing the specific strengths and expertise of the teachers but also to circumvent resource constraints. It is important, however, to recognize that teaching itself is a highly professional job and requires teachers to master many different teaching skills and to dedicate a lot of effort. It becomes even more challenging when new technologies are involved and the diversity of learners continues to increase.

\section{Competency Based Assessment}

Traditionally, assessment is often standardized (or formalized) in terms of both time and location. It is also tied to the course content designed by the instructor. For example, students undertake their final exams together at the same time in an examination room at the end of the course. Thus, instructors play the roles of both teaching the course contents and assessing the learners' learning outcomes. However, "assessment involves more than just measurement. ...to systematically collecting and analyzing information ... interpreting and acting on information about learners' understanding and/or performance relative to educational goals" (Shute and Ventura 2013, p9). With advances in information technology, a number of changes can be observed in education that have impact on these assessment roles of the instructors. For example, course materials can 
now be delivered and shared through the Internet where the materials can be accessed anytime and anywhere. The structure of the learning contents is typically broken into smaller units, and learners can choose units that suit their levels and interests. This also reduces the length of learning time for each unit and allows for learning to take place at the time and pace suitable to individual learner's needs. The timeline of studying a particular course and for an overall program would also be reduced, making it different from one learner to another. This has direct implications for assessment, as it does not fit the traditional form of assessment that requires all students to complete assessment at the same time (and in the case of final examination, at the same location). The assessment should be different from this traditional form. As Shute and Ventura (2013) observe, “... having different purposes and procedures for obtaining information assessments may be differentially referenced or interpreted - for instance, in relation to normative data or a criterion" (p10).

We propose that, in future, the assessment process would be separated from courses or programs to align with the changes in the learning process. This is similar to evidence-centered assessment design (ECD) that informs the design of valid assessments and yields real-time estimates of students' competency levels across a range of knowledge and skills (Shute and Ventura 2013, p24). It also considers learners' multidimensional competencies by collecting and assessing their knowledge, skills, and other attributes (Shute and Ventura 2013). The roles of the instructors would also change from both teaching the course content and assessing performance to primarily supporting the learners in developing certain levels of competence. A possible solution is for the formal assessment to be conducted by an independent unit or organization. They would design, organize, and conduct assessments of individual learner's competency (or of small groups, as the need may be). They would track the competency changes not only for individual subjects but over the overall learning portfolio mentioned above, using analytics techniques, in order to identify the issues that transcend beyond single subjects and individual teachers. This is similar to the approach typically used in the domain of learning English as a second language. Learners can take language courses, or go through self-learning by accessing learning content from YouTube, audio tapes and other resources. Their English proficiency level is then assessed by an authorized organization, such as Educational Testing Service (ETS), International English Language Testing System (IELTS) and alike.

In summary, as Woolf (2010) indicate, assessment of learners' knowledge, skills, and other attributes will be seamless and ubiquitous. The assessment methods need to respond to the changing learning processes. They should focus on assessing competencies that include both knowledge and skills, compared to traditional assessment approaches that have largely focused on memorization and conceptual understanding (Woolf 2010). The learner models will transform into competency based assessment in order to adapt to the nuances of changing needs of the learners, such as being able to undertake assessment anytime and anywhere, support assessment of competencies in collaborative activities, and developed in such a way that they are "plagiarism-proof."

\section{Education in the Service Economy}

While the world is increasingly becoming flat and the service economy has swept all over the world (Friedman 2005), our present education systems still embrace a 
traditional style. Traditional education has focused on a "Product-Oriented" approach that puts more importance on static instructional quality delivery than on the perception of the learners. This philosophy may have worked in a closed and domestic context, but it is not feasible in today's developed global environment.

Education itself needs to be opened to the world and be operated globally, making education a global market. From a marketing point of view, business models nowadays have forced educators to rethink how they can educate learners to be successful in the new global village. Competition is inevitable. There is growing impact of new business models, such as MOOCs - the newly emerging education system that does not require any tuition fees from students unlike traditional schools. This is forcing educators to rethink the way education is delivered. These new systems rely on revenue from certification, advertisement and profiling. While these systems suffer, at least for now from the lack of personalization, high dropout rates, difficulty of teaching hands-on topics, such as programming, where individual feedback is critical for learners in their impasses, and so on, they have still proven to be quite successful; an open course can accommodate hundreds and thousands of students, ten or even hundred times more than traditional schools. Learners are turning their heads towards these trendy initiatives, and in turn, making them financially much stronger than traditional schools. If the old-fashioned schools do not adapt to such changes and reengineer their approaches, they will face the risk of being diminished from this global and open market.

A new concept of "Education-as-a-Service" is emerging as an approach to deal with the challenges of global and open market. Educational resources in this approach are made easily accessible to global learners by delivering them as a service. From this perspective, one can expect the traditional education organizational structure and teaching processes to be radically changed, where configurable and modularized functional units are identified, divided, remixed, reused and rearranged, in order to provide the best possible learning experience to the learners. For example, lectures may be separated from the course itself. Some of the lectures may be given by a teacher other than the teacher responsible for the course. This is to leverage on the specific expertise of different teachers. Assessments may be separated too, where a third party may conduct the tests instead of the course teacher, in similar fashion as Scholastic Aptitude Test (SAT) or Graduate Record Examination (GRE). Social interaction could also be monitored to analyze even the smallest knowledge that learners gain during social interactions, and how that knowledge can be linked with the learner's previously learnt knowledge. So, the "Education-as-a-Service" approach can reengineer the traditional organizational structure of academia, which embeds all functions in one environment, to a federated approach where many different providers provide different functional education units, according to their unique expertise.

While "Education-as-a-Service" takes an organizational view, "Learning-as-aService" takes the learner's viewpoint and considers the learner's learning experience. Focusing on learner-centered learning, the learner's knowledge map becomes more self-directed than teacher-instructed. This change requires reconsideration of service flow (aka the learning process). In smart learning environments, learners would have different service choices at different learning stages, where these services are provided by different educational facilities, either online or physically. For example, learners could choose to learn "Introduction to Calculus" from one school with a teacher known for introducing the topic with fun. They can then continue on with learning Differential 
Calculus from another school from a teacher who is famous for serious teaching using practical examples and exercises. After learning the contents, the students may go to an organization for their assessment and get a certificate. These new scenarios of "Education-as-a-Service" and "Learning-as-a-Service" provide learners with more flexibility than traditional schools. This allows them to aggregate different services at their own pace, resulting in the learners following different learning paths and solutions. Analyzing how the learners (aka consumers in the "service" approach) experience the service of learning holistically and how they reflect and stick to a service, will inform new business models for the education-as-service providers.

\section{The Reorganization of Schooling}

Last but not least, smart learning environments require critical analysis and most likely, reorganization of existing educational systems with a view to benefit from the recent advancements in technologies that support learning in pervasive and ubiquitous environments. This section will examine several examples of these new approaches that may result in the formation of new schooling approaches.

\section{Self-Directed Schooling}

Students in traditional schools are typically compelled to accept courses, examination periods, and even teachers, as they are pre-determined by the school. The absence of self-directed schooling in typical traditional schooling means the learners are forced to study what schools can offer and how they decide to teach. These practices do not allow for customization of learning processes, taking into account the individual learner's strengths and weaknesses, which has implications on the future career choices of the learners. Self-directed schooling is a self-initiated process of learning that stresses the ability of individuals to plan and manage their own learning, an attribute or characteristic of learning with personal autonomy as shared by Caffarella (1993). It has the potential to shrink the learning gaps between students and provide better alignment to a school's curriculum to differences in individual learners. Although there is some truth in Kirschner and van Merriënboer (2013) skepticism about whether learners know best (indicated in their paper - "Do Learners Really Know Best? Urban Legends in Education") we still think that smart learning environments of the future should employ a self-directed schooling approach to enable learners to pursue their own options about what, how and when they want to learn. Enabling learners to exercise their own options will not only contribute towards better customization of content, timing and course plan to suit the needs of the individual learners, but will also improve the learning experience where learners will enjoy the flexibility of choosing the group mates of their own choice and their favorite/suitable teachers. We also believe that having self-directed schooling would have direct impact on motivation and other affective aspects of the learners.

\section{Adaptation to Individual Differences}

Learners nowadays have multiple sources at their disposal to retrieve learning resources, such as open educational resource repositories, Wikipedia, MOOCs, and even 
content from TED talks, YouTube, and iTunes U. Accessing these additional learning resources has never been so easy. Learners have the opportunity to acquire mastery of different topics with ease, without having to rely on the teacher in a classroom. This situation makes learners much more diverse than ever in how they go about achieving their learning objectives. Individual differences nowadays are caused not only by learners' background, competence, gender, personality, cognitive and metacognitive ability and learning progress, but also by the possibility of being able to access different learning resources easily (Kinshuk 2014). Providing an instructional design that can accommodate the needs of all the learners is a very challenging task. The availability of alternative learning resources is continuing to grow in all subject areas and is forcing traditional schools to reconsider how they support the learning process.

Due to the diversity of individual differences, instructors in traditional schools face difficulty in designing curriculum that can cater for every single learner in the classroom. Learners' learning autonomy is a trend that would define the future educational approaches. Schools need to respond to this trend by adopting various features of smart learning environments that support adaptive and personalized learning through innovations in technologies. For example, current learning management systems (LMS) could evolve into intelligent personal learning environments (iPLE) that are capable of personalizing instruction to each learner's needs. Learning methods could also aim at providing intelligent learning supports (iLS) for individual learners. Hence, future schools need to consider how to effectively utilize learning technologies and provide a curriculum that meets the needs and demands of different learners.

\section{Formal Learning Revolution}

Traditional educational approaches are categorized as formal education and informal education. Formal education is classified as the learning that takes place within a school curriculum, whereas informal education is identified as everything else. With advances in technology and the emergence of "opportunistic learning" situations in ubiquitous environments, this distinction is proving to be very artificial. Increasingly, there is ubiquitous availability of mobile devices at almost every location and situation, giving ready access to information as and when the learners need to learn. Learners have frequent interactions in a variety of social media, resulting in micro-learning opportunities, and an abundance of resources available through the always-on Internet. This means that the ratio between formal learning and informal learning is changing rapidly (ASTD 2008; du Bois-Reymond 2003). Even in the past learners had already spend significant time on informal learning activities, and the ratio of informal learning to formal learning is only going to increase in the future with increasing availability of higher bandwidth, richer media, more communication channels, and greater content variety. For example, learners may increasingly decide to spend more time learning from informal channels, e.g. MOOCs or game-based learning, than learning from formal channels such as attending lectures in a classroom. This tendency will squeeze the time of formal learning even further. Schools will need to adapt to this change to remain viable in future.

Once formal learning and informal learning interweave, schools and teachers would need to embrace this combination and find their way out of a mindset where formal learning was the primary means for learning. Smart learning environments treat this 
trend of rising informal learning positively and not as a threat. With diminishing boundaries between formal and informal learning, and the focus on informal learning increasing, we may not need to distinguish these two learning formats separately in the future. Today's informal learning would become tomorrow's formal learning. There are two possible directions this development can take. As a result, formal learning and informal learning may merge and become one "seamless-learning" environment. Various methodologies and approaches of these two learning formats may combine to provide a more comprehensive learning experience to the learners.

A second possibility is that there would always be a unique space for informal learning, but the applicable domain for informal learning would be in "just-in-time" settings. In such contexts, people will learn certain knowledge in a timely manner whenever needed, for example, learning how to bake a cake for Christmas, or fixing a kitchen sink when it breaks. Nevertheless, the emergence of informal learning along with the awareness among teachers and learners, suggests that formal and informal learning will be balanced in the overall future education system. It is also becoming clear that the decision regarding whether to use formal learning or informal learning will be based on the needs of the individual learners and not on some pre-defined arrangement of schools and instructors. As a consequence, the need for a new kind of schooling is on the rise.

\section{Conclusion}

This paper discusses a futuristic vision for smart learning environments. These environments are expected to break the boundaries of the classroom and enable the detection of the learner's location, environment, proximity and situation. This would provide a fully contextualized learning process in order to provide learners with learning scenarios in their own living and work environments, leading to significantly better learning experiences.

Research on smart learning environments is reaching a maturity point where it will be able to provide authentic learning through seamless integration of physical objects available in the learner's vicinity with virtual information in real-time. Also, competency is becoming a key indicator of success while performing tasks. Workforce training and performance appraisal are indispensable components in technologyenabled and resource-rich industries, as they are inherently linked with recruitment, retention, succession planning and other talent management considerations in human resource management. From this perspective, education is becoming a global commodity, which will attract private sector involvement, pushing future educational processes through reengineering (whether automated or not) into processes that cater for individual needs and the requirements of individual career development. One possible scenario is the separation of instructors' teaching process, learners' learning process, assessment and accreditation. In other words, learners would be controlling their own learning process, choosing their own teachers, and undertaking assessment and accreditation at their own time. This phenomenon, enhanced by the emergence of technological advances, has given rise to smart learning environments, where learning and working are merged together. These environments hold the key to the future of education. 
While advances in technology and computing research in recent years are promising for the implementation of smart learning environments, there are technological as well as social challenges that researchers and practitioners will need to overcome. Learning analytics, for example, is still very much in its infancy, particularly with respect to scaling up the real time processing of big data in order to understand the immediate context of a large number of individual learners and to enable teachers to help them. These environments also challenge the existing educational practices that have been used for decades if not centuries and push teachers as well as educational experts out of their comfort zone by making them aware of the limitations of teaching and assessment practices and how they can be improved through these new possibilities. Existing policies also become a barrier to improving education that these environments allow, as they are primarily geared towards old educational paradigms. Tackling these challenges will require concerted efforts of various stakeholders at different levels: teachers at the grassroots level, policy makers, children and parents and in fact all people, industry and professions.

\section{References}

Abowd, G. D., Dey, A. K., Brown, P. J., Davies, N., Smith, M., \& Steggles, P. (1999). Towards a better understanding of context and context-awareness. In H.-W. Gellersen (Ed.), Handheld and ubiquitous computing (pp. 304-307). Springer Berlin Heidelberg. Retrieved from http://link.springer.com/chapter/ 10.1007/3-540-48157-5_29

ASTD. (2008). Tapping the potential of informal Learning. Alexandria, VA: ASTD. Retrieved from https:// www.td.org/Publications/Research-Reports/2008/2008-Tapping-the-Potential-of-Informal-Learning

Bell, P., Lewenstein, B., Shouse, A. W., \& Feder, M. A. (2009). Learning Science in Informal Environments: People, Places, and Pursuits. Washington, DC: National Academies Press. Retrieved from http://www. nap.edu/catalog/12190/learning-science-in-informal-environments-people-places-and-pursuits

Boulanger, D., Seanosky, J., Kumar, V., Kinshuk, Panneerselvam, K., \& Somasundaram, T. S. (2015). Smart Learning analytics. In G. Chen, V. Kumar, Kinshuk, R. Huang, \& S. C. Kong (Eds.), Emerging issues in smart Learning (pp. 289-296). Springer Berlin Heidelberg. Retrieved from http://ink.springer.com/ chapter/10.1007/978-3-662-44188-6 39

Caffarella, R. S. (1993). Self-directed learning. New Directions for Adult And Continuing Education, 1993(57), 25-35.

Chan T.-W., Roschelle J., Hsi S., Kinshuk, Sharples M., Brown T., Patton C., Cherniavsky J., Pea R., Norris C., Soloway E., Balacheff N., Scardamalia M., Dillenbour P., Looi C.-K., Milrad M., Hoppe U., \& G1:1 Members (2006). One-to-one technology-enhanced learning: an opportunity for global research collaboration. Research and Practice in Technology Enhanced Learning, 1(1), 3-29.

Chao, K. J., Huang, H. W., Fang, W. C., \& Chen, N. S. (2013). Embodied play to learn: exploring kinectfacilitated memory performance. British Journal of Educational Technology, 44(5), E151-E155.

Chen, H. Y. L., \& Chen, N. S. (2014). Design and Evaluation of a Flipped Course Adopting the Holistic Flipped Classroom Approach. In 2014 I.E. 14th International Conference on Advanced Learning Technologies (ICALT) (pp. 627-631).

Chen, N. S., \& Fang, W. C. (2014). Gesture-Based Technologies for enhancing Learning, In The New Development of Technology Enhanced Learning (pp. 95-112). Berlin Heidelberg: Springer.

Chen, N. S., Ko, H. C., Kinshuk, \& Lin, T. (2005). A model for synchronous learning using the internet. Innovations in Education And Teaching International, 42(2), 181-194.

Chen, Y., Wang, Y., Kinshuk, \& Chen, N. S. (2014). Is FLIP enough? Or should we use the FLIPPED model instead? Computers \& Education, 79, 16-27.

Cheng, I. L., Chew, S. W., \& Chen, N. S. (2015). Kaleidoscopic Course: The Concept, Design, And Implementation Of The Flipped Classroom. Berlin: Springer.

Chew, S. W., Cheng, I. L., \& Chen, N. S. (2015). Yet another perspectives about designing and implementing a MOOC. Berlin: Springer. 
Clayton-Pedersen, A. R., \& O’Neill, J. L. (2005). Curricula Designed to Meet 21st-Century Expectations. In Educating the net generation (P. 9.). Boulder, CO: Educause. Retrieved from http://digitalcommons. brockport.edu/bookshelf/272/

Conner, M. (2008). Informal learning. Available atwww.agelesslearner.com. - Google search. Retrieved October 28, 2015, from http://marciaconner.com/resources/informal-learning/

Cross, J. (2011). Informal Learning: Rediscovering the Natural Pathways That Inspire Innovation and Performance. Hoboken: John Wiley \& Sons. Retrieved from https:/www.coe.int/t/dg4/youth/Source/ Resources/Documents/2003_links_formal_NFE_en.pdf

Dabbagh, N., \& Kitsantas, A. (2012). Personal Learning environments, social media, and self-regulated learning: A natural formula for connecting formal and informal learning. The Internet and Higher Education, 15(1), 3-8.

du Bois-Reymond, M. (2003). Study on the links between formal and non-formal education. Strasbourg: Directorate of Youth and Sport of the Council of Europe.

Friedman, T. L. (2005). The world is flat: A brief history of the twenty-first century. New York: Farrar, Straus and Giroux.

Fulton, K. (2012). Upside down and inside out: Flip your classroom to improve student learning. Learning \& Leading with Technology, 39(8), 12-17.

Hastie, M., Hung, I. C., Chen, N. S., \& Kinshuk (2010). A blended synchronous learning model for educational international collaboration. Innovations in Education And Teaching International, 47(1), 924.

Hung, I. C., Lin, L. I., Fang, W. C., \& Chen, N. S. (2014). Learning with the body: An embodiment-based learning strategy enhances performance of comprehending fundamental optics. Interacting with Computers, 26(4), 360-371. doi:10.1093/iwc/iwu011.

Hwang, G.-J. (2014). Definition, framework and research issues of smart learning environments - a contextaware ubiquitous learning perspective. Smart Learning Environments, 1(1), 4. doi:10.1186/s40561-0140004-5.

Johnson, L., Adams, S., \& Cummins, M. (2012). The 2012 horizon report. Austin, Texas: The New Media Consortium.

Kaufmann, H. (2003). Collaborative augmented reality in education. Vienna, Austria: Institute of Software Technology and Interactive Systems, Vienna University of Technology.

Kay, J. (2008). Life-long Learning, learner models and augmented cognition. In B. P. Woolf, E. Aïmeur, R. Nkambou, \& S. Lajoie (Eds.), Intelligent Tutoring Systems (pp. 3-5). Berlin: Springer.

Kinshuk (2014). Roadmap for adaptive and personalized learning in Ubiquitous environments. In Ubiquitous Learning Environments and Technologies (pp. 1-13). Heidelberg: Springer.

Kinshuk (2015). Smart learning/ecology of education/.... Personal blog. Retrieved from http://www.kinshuk. info/2015/10/smart-learning-ecology-of-education/.

Kinshuk (2016). Designing adaptive and personalized learning environments (p. eISBN: 978-1-315-795492). New York, NY: Routledge.

Kirschner, P. A., \& van Merriënboer, J. J. (2013). Do learners really know best? urban legends in education. Educational Psychologist, 48(3), 169-183.

Kumar, V. S., Kinshuk, Dr Clemens, C., \& Harris, S. (2015a). Causal Models and Big Data Learning Analytics. In Ubiquitous Learning Environments and Technologies (pp. 31-53). Heidelberg: Springer.

Kumar, V. S., Kinshuk, D., Somasundaram, T. S., Boulanger, D., Seanosky, J., \& Vilela, M. F. (2015b). Big data Learning analytics: A new perpsective. In Ubiquitous Learning Environments And Technologies (pp. 139-158). Heidelberg, Germany: Springer.

Kumar, V., Boulanger, D., Seanosky, J., Kinshuk, Panneerselvam, K., \& Somasundaram, T. S. (2014). Competence analytics. Journal of Computers in Education, 1(4), 251-270.

Leavitt, M. C. (2006). Team teaching: benefits and challenges. Stanford University's Newsletter on Teaching, $16(1), 1-4$.

Li, B. P., Kong, S. C., \& Chen, G. (2015). A study on the development of the smart classroom scale. In Emerging issues in smart learning (pp. 45-52). Heidelberg: Springer. Retrieved from http://link.springer. com/chapter/10.1007/978-3-662-44188-6 6

Malcolm, J., Hodkinson, P., \& Colley, H. (2003). The interrelationships between informal and formal learning. Journal of Workplace Learning, 15(7/8), 313-318.

McDaniel, E. A., \& Colarulli, G. C. (1997). Collaborative teaching in the face of productivity concerns: the dispersed team model. Innovative Higher Education, 22(1), 19-36.

McLaughlin, J. E., Roth, M. T., Glatt, D. M., Gharkholonarehe, N., Davidson, C. A., Griffin, L. M., Esserman, D. A., \& Mumper, R. J. (2014). The flipped classroom: A course redesign to foster learning and engagement in a health professions school. Academic Medicine, 89(2), 236-243. 
McNeely, J. L. (2005). Using Technology as a Learning Tool, Not Just the Cool New Thing. In Educating the net generation (pp. 4.1-4.10). Boulder, Colo.: EDUCAUSE, c2005. 1 v.(various pagings): illustrations. Retrieved from http://digitalcommons.brockport.edu/bookshelf/272/

Mottus, A., Kinshuk, Graf, S., \& Chen, N.-S. (2015). Use of Dashboards and Visualization Techniques to Support Teacher Decision Making. In Kinshuk, \& R. Huang (Eds.), Ubiquitous Learning Environments and Technologies, (pp. 181-199). Heidelberg: Springer.

Mubin, O., Shahid, S., \& Bartneck, C. (2013). Robot assisted language Learning through games: A comparison of two case studies. Australian Journal of Intelligent Information Processing Systems, 13(3), 9-14.

Paquette, G., Mariño, O., Rogozan, D., \& Léonard, M. (2015). Competency-based personalization for massive online learning. Smart Learning Environments, 2(1), 1-19.

Price, J. K. (2015). Transforming learning for the smart learning environment: lessons learned from the Intel education initiatives. Smart Learning Environments, 2(1), 16. doi:10.1186/s40561-015-0022-y.

Riddle, R. (2012). MOOCs: What role do they have in higher education? Retrieved 2015, 14 October from https:/cit.duke.edu/blog/2012/09/moocs-what-role-do-they-have-in-higher-education/

Schilit, B., Adams, N., \& Want, R. (1994). Context-aware computing applications. In Mobile Computing Systems and Applications, 1994. WMCSA 1994. First Workshop on (pp. 85-90). IEEE. Retrieved from http://ieeexplore.ieee.org/xpls/abs_all.jsp?arnumber=4624429

Shute, V. J., \& Ventura, M. (2013). Stealth assessment: Measuring and supporting learning in video games. Cambridge: MIT Press.

Sitzmann, T. (2011). A Meta-analytic examination of the instructional effectiveness of computer-based simulation games. Personnel Psychology, 64(2), 489-528.

Spector, J. M. (2014). Conceptualizing the emerging field of smart learning environments. Smart Learning Environments, 1(1), 2.

Tobias, S., Fletcher, J. D., \& Wind, A. P. (2014). Game-based learning. In In Handbook of research on educational communications and technology (pp. 485-503). New York: Springer.

Wikipedia (n.d.). Augmented Reality. Retrieved from https://en.wikipedia.org/wiki/Augmented_reality.

Wirth, K. R., \& Perkins, D. (2008). Learning to Learn. Retrieved from http://geology.wwu.edu/dept/faculty/ hirschd/courses/2012/winter/306/handouts/learning.pdf

Woolf, B. P. (2010). A Roadmap for Education Technology. Retrieved from https://hal.archives-ouvertes.fr/ hal-00588291/ 